\title{
Development and validation of the specific instrument for assistance complexity of puerperal and newborns: Fantinelli Scale
}

Alessandra Andrade Fantinelli 1

https://orcid.org/0000-0002-3176-9491

Rosalia Figueiró Borges 2

https://orcid.org/0000-0002-2536-7832

Renato Tetelbon Stein 3

https://orcid.org/0000-0003-0269-0757

Rossano Sartori Dal Molin 4

https://orcid.org/0000-0003-1012-1183

\author{
Cristian Roncada 5 \\ iD https://orcid.org/0000-0003-3782-4911
}

\footnotetext{
1-3,5 Pontifícia Universidade Católica do Rio Grande do Sul. Av. Ipiranga, 6681.Prédio 60. 2º andar. Bairro Partenon. Porto Alegre, RS, Brasil. CEP: 90.619-900. E-mail: crisron@gmail.com

2 Universidade do Vale do Rio Sinos. São Leopoldo, RS, Brasil.

4 Centro Universitário da Serra Gaúcha. Caxias do Sul, RS, Brasil.
}

\begin{abstract}
Objectives: to develop and validate a care complexity assessment system adapted for mothers and newborns, based on two pre-existing scales.

Methods: this is a cross-sectional study of psychometric validation of instruments, applied in a roomming-in, in 2016. The instrument has 13 indicators, submitted to the evaluation of a panel of judges for validation. For the psychometric analysis of the instrument, five criteria were adopted: a) internal consistency through Cronbach's alpha $(\alpha C)$; (b) intraclass correlation coefficient (ICC); c) correlation between categorical items, mediating Kendall correlation; d) ceiling and floor effect; e) Kaiser-Meyer-Olkin test.

Results: after evaluating the judges on the categories, the agreement was satisfactory, being equal to or greater than $80 \%$. The mean total score of the 13 items was $22.5 \pm 4.2$, with an intermediate level score of $52.9 \%$. For psychometric validation purposes, the instrument presented $\alpha$ C scores of 0.73 points, between minimum items of 0.70 and maximum of 0.74 points. In the correlation of $\alpha C$ by items and the total score, the instrument showed high relationships ( $r 2: 0.84)$. In the ICC assessment of 0.73 points $(C 195 \%=0.71-0.75 ; p<0.001)$.

Conclusion: the questionnaire presented psychometric indicators of acceptable content validity, with statistical evidence of reliability, obtained by satisfactory inter-rateragreement.

Key words Validation, Neonatal nursing, Rooming-in care
\end{abstract}

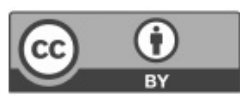




\section{Introduction}

The increasing complexity in care production processes and changes in the demand for patient care in hospital area have required restructuring in health organizations and management models.1,2 This context has become a challenge for the management of health institutions in Brazil, as effective and efficient assistance needs to be met with adequate management of human resources. ${ }^{3}$ In this sense, it is considered important to discuss issues related to the degree of dependence of patients, with regard to nursing assistance, as well as about its impact on the workload of the nursing team. ${ }^{3}$

The concept of patient classification system (PCS), in health practice, contributes to the improvement of models used to determine the workload of the nursing team, valuing the average work time dedicated to patients classified in different categories of care. This enables the adequacy of methods used until then to determine costs of the assistance provided. 4 For this reason, the system has been considered an essential instrument of administrative practice, providing information for the decisionmaking process regarding thecosts of nursing care, organization of services and planning of nursing care. 4

The PCS is a process in which one seeks to categorize patients according to the amount of nursing care required, that is, based on the complexity of the care provided.5 This classification process, according to Perroca, 6 produces a data source that can be used for the qualitative and quantitative planning of human resources, as well as the material resources necessary to ensure safe nursing care. In addition, using a patient classification system allows to know the profile of users and to plan care in a more individualized way, focused on the needs of patients and the nursing team. ${ }^{6}$

Fugulin et al. ${ }^{4}$ classify patients according to the degree of dependence on nursing, being extremely useful for the improvement of official parameters related to the theme of dimensioning nursing staff in hospital institutions. ${ }^{6}$ Thus, the central point of the study was to develop and validate a scale that contemplates the evaluation of the puerperal woman in its entirety, focusing on the mother-baby binomial (Fantinelli Scale). An evaluation system of care complexity was developed for the puerperal woman, using the evaluation criteria of the Fugulin Method ${ }^{7}$ and $\mathrm{UNICEF}^{7}$ precepts based on breastfeeding as a reference. In this sense, this study intends to readapt the evaluation criteria more broadly, contemplating significant aspects for the integral and holistic evaluation of the puerperal woman and the newborn. The adapted scale, which received the name of Fantinelli Scale, presents criteria that will contribute to the planning of the dimensioning of personnel, as well as to the readjustment of the nursing team regarding workload and time to dismiss the patients. Thus, the aim of this study is to develop and validate a care complexity assessment system adapted for puerperal women and newborns cared for in the rooming-in.

\section{Methods}

This is a cross-sectional, descriptive and analytical study, for the purpose of developing and validating a specific instrument to assess the care indicator in health service, both for identification and for controlling the degree of complexity of care required by the puerperal women and newborns.

The study was developed from July 2016 to November 2016. The survey was performed on the puerperal women and their newborns, hospitalized in the rooming-in, in a private hospital located in the South Zone of the city of Porto Alegre / RS. As exclusion criteria, we considered hospitalized mothers who were unable to participate in the study due to medical reasons.

After reviewing the literature and identifying the basic needs of the puerperium, 13 assessment indicators were created, such as: mental status, therapeutics, feeding, elimination, vital signs, wander, body care, skin integrity, mother's general observations, baby position, latch-on and suction. Each indicator item has a gradation of increasing intensity of care complexity, so that the first item corresponds to the lowest level of care complexity and the last to the maximum level of complexity. Each of these indicators is subdivided into 4 items, on a Likert scale, graded from one to four, which sum can vary from 13 to 52 points.

In order to homogenize its application, different values were assigned to each level of dependence in relation to the care provided and the time available to the patient. The sum of values obtained in each area and the definition of each care category determines the care complexity to be provided to the patient. Minimal care was considered between 13 and 19 points; intermediate care, from 20 to 26 points; semi-intensive care, from 27 to 33 points; intensive care, above 34 points. The adapted scale follows the same definitions as the care categories of the Fugulin scale. 6

For content validation purposes, the instrument was sent to a nursing group (judges), consisting of 
seven members, with extensive professional experience, guaranteeing the participation of specialists in the maternal and child issue (with a postgraduate degree in pediatric nursing or in obstetrics or in maternal and child nursing). These participants had a minimum professional experience of five years in the practice or teaching of maternal and child nursing, since knowledge of the subject was an essential condition for this work.

To analyze the consistency of content and related references, a form was structured with three adjustment options: a) item according to the theme, with no need for adjustment or exclusion; b) item according to the theme, with adjustment needs and c) item without agreement with the theme, requiring exclusion or replacement. Among the 13 items explored, none received attribution (c), only concepts $(\mathrm{a} / \mathrm{b})$ were considered. Thus, the concept assignments (b) received adjustments regarding the researchers' suggestions. 8

Data were organized in a table in the Microsoft Access database (Microsoft Corporation, Redmond, Washington, United States of America), version 2013 and exported to SPSS statistical software (Statistical Package for the Social Sciences, New York, United States of America) version 20 for Windows. The following tests were carried out: Kaiser-Meyer-Olkin criterion (KMO), for analysis of the inverse correlation matrix; Bartlett's sphericity test, to test correlated hypotheses, and the Varimaxrotation test, in order to analyze the factor loads of each domain; Cronback's $\alpha$ coefficient $(\alpha C)$, intraclass correlation coefficient (ICC) and Kendall's correlation for the purpose of validating the internal consistency of the instrument. Data were expressed by absolute and relative frequencies for categorical variables and standard deviation for continuous variables.

In the statistical analysis, Cronbach's alpha $(\alpha \mathrm{C})$ was used, ${ }^{9}$ which assesses whether an instrument is able to always measure what it is intended to measure in the same way, performing an average correlation between questions and answers. Acceptable values were used for scores $\alpha-C>0.70$ and $<0.95$. In the correlation between categorical items, Kendall's correlation was used, whose acceptable values are $r \geq 0.310$ and the intraclass correlation coefficient (ICC), 10 in order to measure the homogeneity of measurements. This is useful for interpreting the proportion of total variability attributed to the measured object, adopting a cut-off point $\geq$ 0.70 for classification of the total score (excellent). For ceiling and floor effects, which evaluate the substantial values of answers, provided that they exceed 20\%, criteria 1 (Agree/Floor) and 5 (Disagree/Ceiling) were used. In the factorial validity of the domains, three tests were applied: the Kaiser-Meyer-Olkin (KMO) test, with acceptable levels $>0.6$, the Bartlett's sphericity test, with acceptable levels of $\mathrm{X}^{2}$ for $p<0.001$ and the Varimaxfactorial rotation test, with acceptable levels $>0.6 .11$

The study was approved by the Research Ethics Committee (REC) of the proposing institution, under the consolidated opinion $\mathrm{n}^{\mathrm{o}} 2.612 .347 / 2018$. All participants signed a Free and Informed Consent Form (FICF).

\section{Results}

To validate the questionnaire, the study was carried out from July to November 2016, and 1,396 puerperal women were evaluated, with mean age of 31.1 \pm 5.7 years and gestational age of $37.9 \pm 2.3$ weeks, predominantly Caucasian $(869 ; 62.2 \%)$ and predominantly in the first pregnancy $(708 ; 50.7 \%)$, through hospitalizations by health insurance $(1,207 ; 86.5 \%)$. Regarding the application of the questionnaire, the average of the total score of 13 items was $22.5 \pm 4.2$, with a classification in the intermediate level in 739 (52.9\%), as shown in Table 1 .

In the factorial assessment of the items by domain, the questionnaire presented values within the acceptable ones for the three tests applied. Thus presented: Kaiser-Meyer-Olk in criterion $(\mathrm{KMO}=0.735)$, Bartlett's sphericity test, showing values of $\mathrm{X}^{2}=p<0.001$ and Varimax rotation test, presenting five factors, with a minimum load of 0.527 and a maximum of 0.765 , as shown in Table 2 .

The $\alpha \mathrm{C}$ was applied for the punctuation of the total score of the 13 items, with scores of 0.73 points and between minimum items of 0.70 and maximum of 0.74 points. In addition, in the $\alpha \mathrm{C}$ correlation by items and the total score, the instrument showed high relations $\left(\mathrm{r}^{2}=0.84\right)$, with minimum relations of $\mathrm{r}^{2}=0.11$ and maximum of $\mathrm{r}^{2}=0.57$, all with significance values $<0.05$. In the evaluation of ICC, the value presented for the total score was considered acceptable, with an ICC of 0.73 (CI95\%= 0.71-0.75; $p<0.001)$, as shown in Table 3 .

In the evaluation of the ceiling and floor effects, ten $(76.9 \%)$ of the items presented values above $20 \%$ for floor effect (I agree) and only two (15.4\%) for ceiling effect (I disagree), as shown in Table 3.

When assessing the correlation between items and through the score of the mean total punctuation (Table 4) only two items of the questionnaire did not show correlations with the total scores of the questionnaire (items 1 and 2). 
Table 1

Overall classification of the 1,396 puerperal women evaluated from July 2016 to November 2016 in Porto Alegre / RS.

\begin{tabular}{|c|c|c|c|}
\hline & $\overline{\mathrm{X}} \pm \mathrm{SD}$ & $\mathbf{N}$ & $\%$ \\
\hline Age of puerperal women (years) & $31.1 \pm 5.7$ & & \\
\hline \multicolumn{4}{|l|}{ Ethnicity/Race } \\
\hline White & & 869 & 62.2 \\
\hline Black & & 326 & 23.4 \\
\hline Brown & & 201 & 14.4 \\
\hline Gestational age (months) & $37.9 \pm 2.3$ & & \\
\hline Number of pregnancies & $1.7 \pm 1.0$ & & \\
\hline First pregnancy & & 708 & 50.7 \\
\hline From 2 to 3 pregnancies & & 647 & 46.3 \\
\hline From 4 to 5 pregnancies & & 37 & 2.7 \\
\hline More than 5 pregnancies & & 4 & 0.3 \\
\hline Newborn (Neonatal) & & 229 & 16.4 \\
\hline \multicolumn{4}{|l|}{ Type of hospitalization/pregnancy } \\
\hline Private & & 105 & 7.5 \\
\hline Health insurance & & 1,207 & 86.5 \\
\hline Others & & 84 & 6.0 \\
\hline \multicolumn{4}{|l|}{ Month of hospitalization/pregnancy } \\
\hline July & & 288 & 20.6 \\
\hline August & & 304 & 21.8 \\
\hline September & & 279 & 20.0 \\
\hline October & & 294 & 21.1 \\
\hline November & & 231 & 16.5 \\
\hline \multicolumn{4}{|l|}{ Care complexity questionnaire } \\
\hline Punctuation of total score & $22.5 \pm 4.2$ & & \\
\hline \multicolumn{4}{|l|}{ Classification of total score } \\
\hline Minimal care & & 406 & 29.1 \\
\hline Intermediate care & & 739 & 52.9 \\
\hline Semi-intensive care & & 245 & 17.6 \\
\hline Intensive care & & 6 & 0.4 \\
\hline
\end{tabular}

Table 2

Factorial test through Kaiser-Meyer-Olkintest, Bartlett'ssphericity test and Varimax rotation test criteria $(n=1,396)$.

\begin{tabular}{|c|c|c|c|c|}
\hline & Question & Factor 1 & Factor 2 & Factor 3 \\
\hline Motility, mobility, activity and wander & Q3 & 0.765 & & \\
\hline Eliminations & Q8 & 0.730 & & \\
\hline Overall observation of mothers and breasts & Q10 & 0.628 & & \\
\hline Baby position & Q11 & 0.716 & & \\
\hline Latch-on & Q12 & 0.619 & & \\
\hline Suction & Q13 & 0.646 & & \\
\hline Feeding & Q4 & & 0.565 & \\
\hline Skin integrity & Q6 & & 0.524 & \\
\hline Behavior, feelings and thoughts & Q7 & & 0.566 & \\
\hline Therapeutics & Q9 & & 0.567 & \\
\hline Mental state and sensory perception & Q1 & & & 0.527 \\
\hline Vital signs & Q2 & & & 0.756 \\
\hline Body care, friction and shearing & Q5 & & & 0.669 \\
\hline
\end{tabular}


Table 3

Evaluation, punctuation and classification of the psychometric analysis, using $\alpha \mathrm{C}$ and ceiling and floor effects of the 13 items of the questionnaire ( $n=1,396)$.

\begin{tabular}{|c|c|c|c|c|c|c|c|c|c|c|c|c|}
\hline \multicolumn{2}{|c|}{ Frequency of answers per item } & \multicolumn{2}{|c|}{ I agree } & \multicolumn{2}{|c|}{$\begin{array}{c}\text { I partially } \\
\text { agree }\end{array}$} & \multicolumn{2}{|c|}{$\begin{array}{l}\text { I partially } \\
\text { disagree }\end{array}$} & \multicolumn{2}{|c|}{ Disagree } & \multirow[t]{2}{*}{$\bar{X} \pm S D$} & \multirow[t]{2}{*}{$r^{2}$} & \multirow[t]{2}{*}{$\alpha C$} \\
\hline & & $\mathrm{n}$ & $\%$ & $\mathrm{n}$ & $\%$ & $\mathrm{n}$ & $\%$ & $\mathrm{n}$ & $\%$ & & & \\
\hline Q1 & Mental state and sensory perception & 1379 & $98.8^{\dagger}$ & 17 & 1.2 & 0 & - & 0 & - & $1.0 \pm 0.1$ & $0.30^{*}$ & 0.74 \\
\hline Q2 & Vital signs & 625 & $44.8^{+}$ & 768 & 55.0 & 2 & 0.1 & 1 & 0.1 & $1.6 \pm 0.5$ & $0.29 *$ & 0.76 \\
\hline Q3 & Motility, mobility, activity and wander & 756 & $54.2^{+}$ & 182 & 13.0 & 173 & 12.4 & 285 & $20.4^{\dagger}$ & $2.0 \pm 1.2$ & $0.61^{*}$ & 0.70 \\
\hline Q4 & Feeding & 1,015 & $72.7^{\dagger}$ & 360 & 25.8 & 19 & 1.4 & 2 & 0.1 & $1.3 \pm 0.5$ & $0.28^{*}$ & 0.72 \\
\hline Q5 & Body care, friction and shearing & 49 & 3.5 & 278 & 19.9 & 1,021 & 73.1 & 48 & 3.4 & $2.8 \pm 0.6$ & $0.29 *$ & 0.72 \\
\hline Q6 & Skin integrity & 57 & 4.1 & 104 & 7.4 & 1,216 & 87.1 & 19 & 1.4 & $2.9 \pm 0.5$ & $0.11^{*}$ & 0.74 \\
\hline Q7 & Behavior, feelings and thoughts & 1,172 & $84.0^{+}$ & 178 & 12.8 & 17 & 1.2 & 29 & 2.1 & $1.2 \pm 0.6$ & $0.23^{*}$ & 0.73 \\
\hline Q8 & Eliminations & 781 & $55.9^{\dagger}$ & 201 & 14.4 & 34 & 2.4 & 380 & $27.2^{+}$ & $2.0 \pm 1.3$ & $0.57^{*}$ & 0.70 \\
\hline Q9 & Therapeutics & 254 & 18.2 & 1,048 & 75.1 & 89 & 6.4 & 5 & 0.4 & $1.9 \pm 0.5$ & $0.29 *$ & 0.72 \\
\hline Q10 & Overall observation of mother and breasts & 1,117 & $80.0^{+}$ & 216 & 15.5 & 53 & 3.8 & 10 & 0.7 & $1.3 \pm 0.6$ & $0.27^{*}$ & 0.72 \\
\hline Q11 & Baby position & 870 & $62.3^{+}$ & 290 & 20.8 & 217 & 15.5 & 19 & 1.4 & $1.6 \pm 0.8$ & $0.52^{*}$ & 0.70 \\
\hline Q12 & Latch-on & 750 & $53.7^{\dagger}$ & 278 & 19.9 & 342 & 24.5 & 26 & 1.9 & $1.7 \pm 0.9$ & $0.48^{*}$ & 0.71 \\
\hline Q13 & Suction & 988 & $70.8^{\dagger}$ & 283 & 20.3 & 101 & 7.2 & 24 & 1.7 & $1.4 \pm 0.7$ & $0.41 *$ & 0.71 \\
\hline
\end{tabular}

\begin{tabular}{|c|c|c|c|c|c|c|c|c|c|c|c|c|}
\hline \multicolumn{2}{|c|}{ Frequency of answers per care } & \multicolumn{2}{|c|}{ Minimum } & \multicolumn{2}{|c|}{ Intermediate } & \multicolumn{2}{|c|}{ Semi-intensive } & \multicolumn{2}{|c|}{ Intensive } & \multirow[b]{2}{*}{$22.6 \pm 4.2$} & \multirow[b]{2}{*}{$0.83 *$} & \multirow[b]{2}{*}{0.73} \\
\hline TS & Total Score & 406 & 29.1 & 739 & 52.9 & 245 & 17.6 & 6 & 0.4 & & & \\
\hline
\end{tabular}

$\alpha C=$ Cronbach's alpha coefficient; $r^{2}=$ correlation of $\alpha C$; * $p$-value of $r^{2}<0.05$

+ ceiling/floor effect for items with a prevalence above $20 \%$ of answers. 
Table 4

Correlation test between items and total score $(n=1,396)$

\begin{tabular}{|c|c|c|c|c|c|c|c|c|c|c|c|c|c|c|}
\hline & Q1 & Q2 & Q3 & Q4 & Q5 & Q6 & Q7 & Q8 & Q9 & Q10 & Q11 & Q12 & Q13 & TS \\
\hline Q1 & 1.00 & 0.05 & $-0.06^{*}$ & 0.00 & 0.04 & -0.01 & -0.03 & $-0.06^{*}$ & -0.03 & -0.01 & -0.03 & -0.04 & -0.03 & 0.00 \\
\hline Q2 & & 1.00 & $-0.29 * *$ & $-0.14^{* *}$ & $0.17^{* *}$ & 0.03 & 0.00 & $-0.18^{* *}$ & -0.01 & -0.03 & -0.10 ** & $0.10^{* *}$ & $-0.10^{* *}$ & -0.01 \\
\hline Q3 & & & 1.00 & $0.38^{* *}$ & 0.32 ** & $0.07^{* *}$ & 0.03 & $0.58^{* *}$ & $0.24^{* *}$ & $0.06^{*}$ & $0.16^{* *}$ & 0.11 ** & $0.13^{* *}$ & 0.54 ** \\
\hline Q4 & & & & 1.00 & $0.15^{* *}$ & -0.02 & $0.17 * *$ & $0.36 * *$ & 0.02 & $0.16^{* *}$ & $0.05^{*}$ & 0.03 & $0.09 * *$ & 0.36 ** \\
\hline Q5 & & & & & 1.00 & $0.06^{*}$ & 0.05 & $0.32 * *$ & 0.24 ** & $0.06 *$ & $0.10^{* *}$ & $0.16^{* *}$ & $0.06^{*}$ & $0.43 * *$ \\
\hline Q6 & & & & & & 1.00 & -0.04 & $0.06^{*}$ & 0.24 ** & 0.03 & $0.06^{*}$ & $0.09 * *$ & 0.04 & $0.18^{* *}$ \\
\hline Q7 & & & & & & & 1.00 & 0.04 & $-0.12^{* *}$ & $0.40 * *$ & $0.27^{* *}$ & $0.17^{* *}$ & $0.26^{* *}$ & $0.25^{* *}$ \\
\hline Q8 & & & & & & & & 1.00 & $0.29 * *$ & $.064^{*}$ & $0.10 * *$ & $0.13^{* *}$ & $0.09 * *$ & $0.55^{* *}$ \\
\hline Q9 & & & & & & & & & 1.00 & 0.00 & $0.17^{* *}$ & $0.23 * *$ & $0.13^{* *}$ & $0.39 * *$ \\
\hline Q10 & & & & & & & & & & 1.00 & $0.33^{* *}$ & 0.17 ** & 0.27 ** & $0.32 * *$ \\
\hline Q11 & & & & & & & & & & & 1.00 & $0.49 * *$ & 0.56 ** & $0.50 * *$ \\
\hline Q12 & & & & & & & & & & & & 1.00 & 0.44 ** & 0.52 ** \\
\hline Q13 & & & & & & & & & & & & & 1.00 & $0.43 * *$ \\
\hline TS & & & & & & & & & & & & & & 1.00 \\
\hline
\end{tabular}

$\mathrm{Q}=$ Question corresponding to the questionnaire number; $\mathrm{TS}=$ Total score of the questionnaire; $* * p$ of $r<0.01$; $p$ from $r<0.05$ to 0.01 ; Kendall's correlation test. 


\section{Discussion}

It is extremely important, in the current context, to develop a specific instrument to assess the specific degree of assistance complexity in the care of puerperal women and their newborns, in order to determine, monitor and evaluate the individualized care needs for each binomial. The use of appropriate tools for this type of patient will be of great help in the management of the nursing service, in the sense of verifying the workload of your team, using resources that allow you to better reevaluate the attention and planning, as well as the distribution in control of the professional staff. Thus, the present study had as its primary objective the development and validation of a specific instrument in order to assess the care complexity for puerperal women and their babies cared for in the rooming-in, based on the form of observation and assessment of breastfeeding recommended in the guidelines of the World Health Organization (WHO), in the United Nations Children's Fund (UNICEF) and the Fugulin Scale.

Among the recommended breastfeeding promotion actions, there is the observation of mother and newborn during breastfeeding. To guide this practice, a breastfeeding observation protocol was developed by UNICEF, in which it is possible to evaluate the desirable behaviors of mothers and babies and other indications of problems perceived by the nurse. 12

The process of validating an instrument is arduous and long, but it is essential that instruments have reliability and validity to minimize the possibility of subjective judgments.13 Validation processes that include careful and systematic steps can guarantee the quality of the results. 14

The construction and validation of instruments that measure the quantity and content of information are essential in an attempt to improve the knowledge of puerperal patients. The clarity index generated by professionals and patients determined that the proposed instrument is easy to understand for the population to be evaluated. $10,15,16$

In assessing clarity, the instrument met the minimum prerequisites for structuring, relevance, credibility and balance, through intelligible, consistent items and expressions befitting the attribute, expressing a single idea to the proposed instrument. $10,17,18$

This can be stated, since only 3 of the 13 questions answered by the nurses had doubts and did not obtain $100 \%$ positive answers, which is equivalent to $80 \%$. Where a high abstention rate was obtained, however, these values were already expected, given that the levels of abstention reported in the literature are 30 to $50 \%$ in the first round and 20 to $30 \%$ in the subsequent ones. 19

The participation of specialist nurses who have extensive professional experience in the areas of care, teaching and research, was essential for the improvement and validation of the instrument. Their expertise contributed to the construction of knowledge, enhancing these dimensions, given the importance of the theme under study.

The experts pointed out activities that were clearly and objectively described and all considered that they were relevant and represented the practice of puerperal nursing care. They also made suggestions related to the following aspects: title of the instrument, standardization of writing style and inclusion of assistance with the binomial mother and baby in the neonatal intensive care unit.

Regarding the validity of the questionnaire content, through factorial analysis of the items by domain, the results showed values within acceptable patterns for the 1,396 tests applied, demonstrating a good factorial correlation between the 13 items and the 4 domains proposed, such as: $(\mathrm{KMO}=0.735$, Bartlett' $s=p<0.001$ and minimum Varimax rotation of -0.527 and maximum of 0.765 ).

The validity of the internal consistency through the Chronbach alpha demonstrates that the application of such a coefficient allows us to evaluate the consistency between items, as well as their responses, providing an estimate of the true viability of an instrument for proper measurements, in which values below 0.70 are considered weak and above 0.95 are redundant. Thus, the values attributed to the $\alpha \mathrm{C}$ coefficient in this study demonstrate that there is good reliability between questions (items) and their answers in the likert scale format $(\alpha \mathrm{C}=0.73)$. When applying the $\alpha \mathrm{C}\left(\mathrm{r}^{2}\right)$ correlation, we found all values above the expected $\geq 0.3$, reinforcing that there is a positive association between items and categories.

The content validation of the instrument for the Assessment of the Degree of Dependence of the puerperal woman and the newborn proved to be relevant, clear and objective, enabling its application in a reliable way, thus being able to contribute as a parameter for the nursing dimensioning. ${ }^{20}$

Regarding the nurses who helped validate the content, an excellent degree of agreement was obtained between them, with a minimum value of 0.72 being found in the guidelines for applying the instrument. Thus, it is considered that the scale proposals considered the needs in relation to what was intended to be questioned, according to the nurses. 
The data regarding internal consistency and reliability determined the questionnaire's homogeneity and stability, demonstrating that multiple applications can generate similar and accurate results. ${ }^{21-23}$ Regarding the sample size, a number of 238 patients hospitalized in rooming-in were used, according to a $95 \%$ confidence level and a sampling error of $5 \%$ per item, proposed in processes of instrument construction and validation. 10,24

The FUGULIN instrument is the validated instrument closest to the proposed context, as it is evaluating, mainly, the hospitalized patient in an inpatient unit. However, the aspects addressed are different from those proposed by the present study under validation.

In addition, in this study, complementary assessments were applied to those analyzed by the two instruments (Fugulin + Observation and Breastfeeding Assessment Form), as in the case of the ceiling and floor effect, being considered an important assessment in the validation process of instruments that use responses in likert format, verifying how much the minimum or maximum alternatives influence the answers of the evaluated person. The values found with the application of the ceiling/floor effects show that 10 items $(76.9 \%)$ obtained prevalence of the minimum answer option (never), which ended up influencing the average of the total questionnaire $22.6 \pm 4.2$.

There is a gap in the literature about other researches, national and international, developed with this type of patients, making it impossible to compare the results obtained. This reality represents limitations for the discussion of this research. The fact that it was also carried out in a single place, that is, only one maternity hospital, can be a methodological limitation.

The future performance of these tests will make it possible to verify their applicability in care and management practice, as well as to correlate each of these activities with the time spent to perform them, in order to constitute an instrument that determines the workload of the nursing team in these units. ${ }^{22}$

Thus, it is suggested to expand the focus on the factors that influence planning and management, considering all the complexity inherent to health services and the dimensioning of personnel as indicators for quality of care and the occurrence of adverse events.

The study made it possible to draw a profile of the unit and hospitalized puerperal women, as well as identifying the days of greatest nursing care demand. Therefore, the identification of the profile of this study unit allows the provision of services in assistance with more quality and with the necessary number of collaborators.

The categorization of nursing care is one of the necessary and important parameters in the management of a health service, since it demonstrates the degree of complexity of the care required by the patient, in addition to guiding a possible need for restructuring the management models in rooming-in. Therefore, access to a specific care category in the rooming-in, for the mother-baby binomial, will bring benefits to the organization in care line.

Analyzing the degree of need for patient care, it was possible to observe a greater concentration in semi-intensive care, followed by minimal, intermediate and intensive care. It is believed that this research has brought contributions to overcome the difficulties related to the proposal of parameters for dimensioning nursing staff in the rooming-in, in view of the excellence of care and safety of patients assisted in this area. 22

Finally, the values obtained in the present study showed that the Fantinelli Scale is a valid instrument for a specific patient classification system for postpartum care, suggesting that the scale can be used in the management of a health service for the classification of these patients hospitalized in the roomingin. Given the good prevalence and, if properly used, it can become a valuable tool for health care indicators in the identification and control of the degree of complexity of care required by the patient, in addition to guiding a possible need for restructuring management models in the rooming-in.

\section{Authors' contribution}

Fantinelli AA contributed to the elaboration of the project, data collection and writing of the manuscript. Borges RF participated in the elaboration of the project and review of the manuscript. Stein RT and Dal Molin RS wrote and revised the manuscript. Roncada C carried out project guidance, statistics, writing and revision of the manuscript. All authors approved the final version of the article. 


\section{References}

1. Magalhães AMM,Riboldi CO, Dall' Agnol CM. Planejamento de recursos humanos de enfermagem: desafio para as lideranças. Rev Bras Enferm. 2009; 62 (4): 608-20.

2. Marquis BL, Huston CJ. Administração e liderança em enfermagem: teoria e prática. 8 ed. Porto Alegre: Artmed; 2015 .

3. Silva KS, Echer IC, Magalhães AMM. Grau de dependência dos pacientes em relação à equipe de enfermagem: uma ferramenta de gestão. Esc Anna Nery. 2016; 20 (3) e201600600.

4. Fugulin FMT, Gaidzinski RR, Kurcgant P. Sistema de classificação de pacientes: identificação do perfil assistencial dos pacientes das unidades de internação do HU-USP. Rev Latino-Am Enferm. 2005; 13 (1): 72-8.

5. Perroca MG. Desenvolvimento e validação de conteúdo da nova versão de um instrumento para classificação de pacientes. Rev Latino-Am Enferm. 2011; 19 (1): 58-66.

6. Perroca MG. The new version of a patient classification instrument: assessment of psychometrics properties. J Adv Nurs. 2013; 69 (8): 1862-8

7. UNICEF. Breastfeeding management and promotion in a baby-friendly hospital: an 18-hour course for maternity staff; 1993. Disponível em: https://www.unicef.org/nutrition/files/BFHI_2009_s3.1and2.pdf

8. Santiago LB. Manual de Aleitamento Materno. Sociedade Brasileira de Pediatria. Barueri, SP: Manole; 2013.

9. Dancey C, Reidy J. Statistics without maths for Psychology: using SPSS for Windows. 3 ed. London: Prentice Hall; 2005.

10. Martins GA. Sobre confiabilidade e validade. Rev Bras Gestão Negócios. 2006; 8 (20): 1-12.

11. Pasquali L. Princípios de elaboração de escalas psicológicas. Rev Psiquiatr Clín. 1998; 25 (5): 206-13.

12. OMS (Organização Mundial da Saúde). Amamentação. Genebra; 2003. [Available from: http://biblioteca.planejamento.gov.br/biblioteca-tematica-1/textos/saudeepidemias-xcampanhas-dados-descobertas/texto-87amamentacao.pdf

13. Vieira AC, Costa AR, Gomes P. Boas práticas em aleitamento materno: Aplicação do formulário de observação e avaliação da mamada. Rev Soc Bras Enferm Ped. 2015; 15 (1): 13-20.

14. Raymundo VP. Construção e validação de instrumentos: um desafio para a psicolinguística. Letras Hoje. 2009; 44 (3): 86-93.
15. Medeiros RKS, Ferreira Júnior MA, Pinto DPSR, Vitor AF, Santos VEP, Barichello E. Modelo de validação de conteúdo de Pasquali nas pesquisas em Enfermagem. Rev Enf Ref. 2015; SerIV (4): 127-35.

16. Gaidzinski RR. Dimensionamento de pessoal de enfermagem em instituições hospitalares. [tese Livre-Docência] São Paulo: Escola de Enfermagem da Universidade de São Paulo; 1998

17. Kurcgant P, Cunha KC, Rapone GR. Subsídios para a estimativa de pessoal em enfermagem. Enfoque (São Paulo) 1989;17(3):79-81.

18. Sommaruga M, Vidotto G, Bertolotti G, Pedretti R, Tramarin R. A self administered tool for the evaluation of the efficacy of health education interventions in cardiac patients. Monaldi Arch Chest Dis. 2003; 60 (1): 7-15.

19. Pasquali L. Instrumentação psicológica: Fundamentos e práticas [Psychological instrumentation: Bases and practices]. Porto Alegre: Artmed; 2010.

20. Macedo ABT. Avaliação da carga de trabalho, estresse psicossocial e resiliência nos profissionais de enfermagem em uma unidade de internação para adultos portadores de germes multirresistentes [dissertação]. Porto Alegre: Universidade Federal do Rio Grande do Sul; 2013.

21. Fugulin FMT, Silva S, Shimizu HE, Campos F. Implantação do sistema de classificação de pacientes na unidade de clínica médica do hospital universitário da USP. Rev Med HU-USP. 1994; 4 (1/2): 63-8.

22. Machado CR, Poz MR. Sistematização do conhecimento sobre as metodologias empregadas para o dimensionamento da força de trabalho em saúde. Saúde Debate. 2015; 39 (104): 239-54.

23. Pilotto DTS, Vargens OMC, Progianti JM. Alojamento conjunto como espaço de cuidado materno e profissional. Rev Bras Enf. 2009; 62 (4): 604-7.

24. Santos NC, Fugulin FMT. Construção e validação de instrumento para identificação das atividades de enfermagem em unidades pediátricas: subsídio para determinação da carga de trabalho. Rev Esc Enferm USP. 2013; 47 (5): 1052-60

Received on May 14, 2019

Final version presented on October 28, 2019

Approved on December 27, 2019 